\title{
PERANCANGAN SISTEM INFORMASI PROFIL SEKOLAH BERBASIS WEB PADA SMA 3 KOTA TERNATE
}

\section{DESIGN OF INFORMATION SYSTEMS WEB-BASED SCHOOL PROFILE IN HIGH SCHOOL 3 TERNATE CITY}

\author{
Ruslan Rajak $^{1}$, Muharto ${ }^{2}$ \\ Program Studi Manajemen Informatika, \\ Politeknik Sains dan Teknologi Wiratama Maluku Utara \\ ruslan.rajak01@gmail.com
}

\begin{abstract}
Abstrak
Sistem informasi banyak digunakan dalam suatu lembaga-lembaga. Misalnya dalam sebuah perusahaan, perkantoran dan pendidikan. Dalam lembaga pendidikan sistem informasi ini bertujuan untuk promosi atau memberikan gambaran umum mengenai profil lembaga pendidikan yang bersangkutan, administrasi, dan fasilitas yang lain, Sekolah Menengah Atas (SMAN) 3 Kota Ternate merupakan salah satu Sekolah dikecamatan Ternate Utara, dalam memberikan informasi sekolah masih dilakukan secara manual yaitu pihak sekolah melakukan sosialisi dan interaksi kepada masyarkat luas seperti profil sekolah, data siswa, data guru, dan informasi jadwal pelajaran. Penelitian ini bertujuan untuk merancang sistem informasi profil sekolah berbasis web pada (SMAN) 3 Kota Ternate. Data yang digunakan adalah data sekunder berupa dokumen-dokumen yang diperoleh langsung dari (SMAN) 3 Kota Ternate. Sistem ini menggunakan bahasa pemrograman HTML, PHP, CSS dan MySQL sebagai databasenya. Sistem ini diharapkan agar mempermudah pihak sekolah dalam memberikan informasi sekolah dan masyarakat dapat melihat Informasi sekolah dimana saja tanpa menunggu pihak sekolah melakukan Sosialisasi secara lansung
\end{abstract}

Kata Kunci : Sistem Informasi, Web, Sekolah

\begin{abstract}
The information system is widely used in some institutions. For example in a company, office, and education. In the educational institution information system is intended for sale or give a general overview about the profile of the institution, administrative and other facilities, High School 3 Ternate City is one of the Schools dikecamatan North Ternate, in providing information on schools still do manually, the schools do socialization and interaction to the public widely as the profile of the school, student data, teacher data, and information timetables. This study aimed to design a system of web-based school profile information on high school 3 Ternate City. The data used are secondary data from documents obtained directly from high school 3 Ternate City. This system uses a programming language HTML, PHP, CSS and MYSQL as the database. This system is expected to facilitate the school in providing information and public schools can see the information without waiting for a school where the schools do Socialization indirectly.
\end{abstract}

Keyword: Information System, Website, School 


\section{PENDAHULUAN}

Pada masa sekarang ini, sistem informasi banyak digunakan dalam suatu lembaga-lembaga. Misalnya dalam sebuah perusahaan, perkantoran dan pendidikan. Dalam lembaga pendidikan sistem informasi ini bertujuan untuk promosi atau memberikan gambaran umum mengenai profil lembaga pendidikan yang bersangkutan, administrasi, dan fasilitas yang lain

Perkembangan teknologi informasi pada saat ini khususnya teknologi internet, banyak potensi dan sumber daya yang bisa dimanfaatkan. Sekarang ini, pemanfaatan teknologi informasi website tidak sekedar sebagai fasilitas bagi dunia pendidikan untuk memperoleh informasi-informasi terbaru mengenai pendidikan terutama di Indonesia, tetapi juga dapat memberikan kesan baik dan profesionalisme bagi sekolah tersebut. (Johari, 2012)

Berdasarkan peraturan pemerintah Nomor 32 Tahun 2013 tentang syarat Sekolah Standart Nasional, salah satunya yaitu "Standar Sarana dan Prasarana adalah kriteria mengenai ruang belajar, tempat berolahraga, tempat beribadah, perpustakaan, laboratorium, bengkel kerja, tempat bermain, tempat berkreasi dan berekreasi serta sumber belajar lain, yang diperlukan untuk menunjang proses pembelajaran, termasuk penggunaan teknologi informasi dan komunikasi". Dengan website sebagai media informasi dan promosi bisa memenuhi syarat sebagai Sekolah Standart Nasional termasuk, yaitu dalam penggunaan teknologi informasi dan komunikasi

Sekolah Menengah Atas (SMAN) 3 Kota Ternate merupakan salah satu Sekolah dikecamatan Ternate Utara, dalam memberikan informasi sekolah masih dilakukan secara manual dengan sosialisasi dan interaksi kepada masyarkat luas seperti profil sekolah, data siswa, data guru, dan informasi jadwal pelajaran.

Sistem Informasi Profil Sekolah Berbasis Web pada SMA Negeri 3 Kota Ternate ini dirancang menggunakan bahasa pemrograman HTML, PHP, CSS dan MySQL sebagai databasenya. Sistem ini diharapkan agar mempermudah pihak sekolah dalam memberikan informasi sekolah dan masyarakat dapat melihat Informasi sekolah dimana saja tanpa menunggu pihak sekolah melakukan Sosialisasi secara lansung

\section{Rumusan Masalah}

Permasalahan penelitian ini adalah: Bagaimana Merancang Sistem Informasi Data Siswa Berbasis Web Pada SMA Negeri 3 Kota Ternate? Bertujuan memberikan kemudahan pada pihak sekolah dalam memberikan informasi sekolah dan masyarakat dapat melihat informasi sekolah dimana saja saja tanpa menunggu pihak sekolah melakukan Sosialisasi secara lansung

\section{LANDASAN TEORI Defenisi Sistem Informasi}

Sistem Informasi adalah kumpulan dari sub-sub sistem yang saling terintegrasi dan berkolaborasi untuk menyelesaikan masalah tertentu dengan cara mengolah data dengan alat yang namanya komputer sehingga memiliki nilai tambah dan bermanfaat bagi pengguna Taufiq (2013).

Menurut Hartono Sistem informasi adalah seperangkat komponen yang saling berhubungan, yang bekerja untuk mengumpulkan dan menyimpan data serta mengolahnya menjadi informasi untuk digunakan (2013) 


\section{Pengertian Web}

situs web adalah sebagai kumpulan halaman-halamanyang digunakan untuk menampilkan innformasi teks, gambar diam atau gerak, animasi, suara dan atau gabungan dari semuanya baik yang bersifat statis maupun dinamis yang membentuk satu rangkaian bangunan yang saling terkait dimana masing-masing dihubungkan dengan jaringan-jaringan halaman (Hyperlink) Saputra (2007)

Website (situs web) adalah merupakan alamat (URL) yang berfungsi sebagai tempat penyimpanan data dan informasi dengan berdasarkan topik tertentu. (Sutarman, 2007)

Www atau world wide web atau web saja merupakan sebuah sistem yang saling terkait dalam sebuah dokumen yang berformat hypertext yang berisi beragam informasi, baik tulisan, gambar, suara, video, dan informasi multimedia lainnya dan dapat diakses melalui sebuah perangkat yang disebut web browser. Untuk menterjemahkan dokumen dalam bentuk hypertext ke dalam bentuk dokumen yang dapat dipahami, maka web browser melalui web client akan membaca halaman web yang tersimpan disebuah web server melalui protokol yang biasa disebut http atau Hypertext Transfer Protocol (Heni Dwi Erinawati, 2012)

\section{Pengertian Website Profil}

Website profil adalah sebuah website yang hanya menampilkan informasi tentang visi, misi, sejarah perkembangan, organisasi, jasa atau produk yang ditawarkan tetapi tidak secara langsung menjual produk hanya sebatas informasi (Jasmadi, 2004)

\section{Pengertian Database}

\begin{abstract}
Database menyatakan merupakan suatu bentuk pengelolaan data yang ditujukan agar pengaksesan terhadap data dapat dilakukan dengan mudah. (Abdul Kadir, 2005)
\end{abstract}

\section{Pengertian HTML}

HTML (Hypertext Markup Language) merupakan salah satu format yang digunakan dalam pembuatan dokumen dan aplikasi yang berjalan di halaman web. Oleh karena itu agar dapat membuat program aplikasi diatas halamn web, terlebih dahulu harus mengenal dan menguasai HTML. Protokol yang digunakan untuk mentransfer data antara web server ke web browser ialah HTTP (Hypertext Transfer Protocol). Protokol ini mentransfer dokumen-dokumen web yang ditulis atau berformat HTML (Hypertext Markup Language) Sunarfri hantono (2002).

\section{Pengertian PHP}

PHP atau yang memiliki kepanjangan PHP Hypertext Preprocessor merupakan suatu bahasa pemograman yang difungsikan untuk membangun suatu website dinamis. PHP menyatu dengan kode HTML, makasudnya adalah beda kondisi. HTML di gunakan sebagai pembangun atau pondasi dari kerangka layout web, sedangkan PHP difungsikan sebagai prosesnya sehingga dengan adanya PHP tersebut, sebuah web akan sangat mudah dimaintenance. PHP berjalan pada sisi server sehingga PHP disebut juga sebagai bahasa Server Side Scripting. Artinya bahwa dalam setiap/untuk menjalankan PHP wajib adanya sebuah server. PHP ini bersifat open source sehingga dapat dipakai secara cuma-cuma dan mampu lintas platform yaitu dapat berjalan pada sistem operasi windows 
maupun linux. PHP juga dibangun sebagai modul pada web server apache dan sebagai binary yang dapat berjalan sebagai CGI Saputra (2011)

\section{Pengertian MySQL}

Secara umum, database berfungsi sebagai tempat atau wadah untuk menyimpan, mengklasifikasikan data secara professional. MySQL bekerja menggunakan SQL Language (Structure Query Language) itu dapat diartikan bahwa MySQL merupakan standar penggunaan database didunia untuk pengolahan data. Saputra (2011). Sedangkan Raharjo (2011:21) MySQL merupakan RDBMS atau (server database) yang mengelolah database dengan cepat menampung dalam jumlah sangat besar dan dapat diakses oleh banyak user.

\section{Pengertian CSS}

CSS atau Cascading Style Sheets adalah sebuah dokumen yang berisi aturan yang digunakan untuk memisahkan isi dengan layout dalam halaman-halaman web yang dibuat. CSS memperkenalkan "template" yang berupa style untuk dibuat dalam mengizinkan penulisan kode yang lebih mudah dari halaman-halaman web yang dirancang. Sedangkan Jayan (2010:2) dalam buku CSS untuk orang awam yang menjelaskan tentang kegunaan CSS adalah untuk mengatur tampilan dokumen HTML, contohnya seperti pengaturan jarak antar baris, teks, warna, dan format border bahkan penampilan file gambar. Kurniawan (2008)

\section{DFD (Data Flow Diagram)}

Data flow diagram atau yang disingkat DFD merupakan suatu diagram yang menggambarkan alir data dalam suatu entitas ke sistem atau sistem ke entitas (Saputra, 46:2013). DFD juga dapat diartikan sebagai teknis grafis yang menggambarkan alir data dan transformasi yang digunakan sebagai perjalanan data dari input atau masukkan menuju keluaran atau output

\section{Flowchart}

Flowchart adalah bagan-bagan yang mempunyai arus yang menggambarkan langkah-langkah penyelesaian suatu masalah. penggambaran secara grafik dari langkah-langkah dan urut-urutan prosedur dari suatu program. Flowchart menolong analis dan programmer untuk memecahkan masalah kedalam segmen-segmen yang lebih kecil dan menolong dalam menganalisis alternatif-alternatif lain dalam pengoperasian.

\section{Enity Relationship Diagram (ERD)}

Entity Relationship Diagram merupakan gambaran sistematis model data yang berisi himpunan entitas dan himpunan relasi yang masing-masing dilengkapi dengan atribut - atribut yang mempresentasikan seluruh fakta.

\section{METODE PENELITIAN}

\section{Teknik Pengumpulan Data}

Menurut Sugiyono (2012), pengumpulan data dalam penelitian dilakukan melalui tiga kegiatan, yaitu observasi, wawancara dan dokumentasi.

a. Observasi,yaitu penelitian langsung atau pengamatan ke objek penelitian untuk mengetahui secara langsung tentang masalah yang dihadapi.

b. Wawancara adalah proses pengumpulan data dengan cara tanya jawab langsung dengan 
pimpinan dan staf SMA Negeri 3

Kota Ternate

c. Dokumentasi dalam penelitian ini dimaksudkan untuk memperoleh data berbentuk dokumentasi, berupa gambar dan foto-foto kegiatan sekolah yang ada di SMA Negeri 3 Kota Ternate

\section{Bahan dan Alat Penelitian}

1. Hardware
a. Processor intel Core i3.
b. Mainbord Intel.
c. RAM 2 GB.
d. Hardisk 500 GB.
e. LCD Lenovo 32 bit
f. Printer Cannon IP2700.

2. Software

a. Sistem operasi windows 7 ultimate

b. Notepad ++

c. Web server XAMPP (Apache, MySQL)

d. Microsoft Office

e. Microsoft Visio

f. Mozilla Firefox

g. Bahasa pemograman $H T M L, P H P$, CSS.

\section{Analysis Sistem}

Al Fatta (2007:44) menyebutkan langkah-langkah yang perlu di lakukan dalam tahapan analisis sistem adalah sebagai berikut:

1. Identifikasi, yaitu langkah pertama yang dilakukan untuk mengidentifikasi sejumlah aspek yang di analisis. Hal yang perlu di lakukan dalam tahapan ini adalah :

a. Identifikasi masalah

b. Identifikasi penyebab masalah

c. Mendesain sistem untuk mencegah masalah

2. Understand, yaitu memahami kerja dari sistem yang ada. Hal-hal yang perlu dilakukan dalam tahapan ini adalah :

a. Menentukan jenis penelitian

b. Menyusun jadwal penelitian

c. Membuat agenda wawancara (interview)

d. Mengumpulkan hasil dan bahan penelitian

\section{Analisa sistem yang berjalan Indetifikasi Masalah}

Sekolah Menengah Atas (SMAN) 3 Kota Ternate merupakan salah satu Sekolah dikecamatan Ternate Utara, dalam memberikan informasi sekolah masih dilakukan secara manual dengan dilakukan sosialisasi lansung secara interaksi kepada masyarakat seperti profil sekolah, data siswa, data guru, dan informasi jadwal pelajaran, sosialisasipun dilakukan hanya 1 kali dalam setahun pada saat penerimaan siswa baru disekolah tersebut, sehingga masyarakat lain yang belum mendapatkan informasi secara lansung dari pihak sekolah harus berkunjung langsung ke sekolah tersebut

\section{Analisa sistem yang diusulkan}

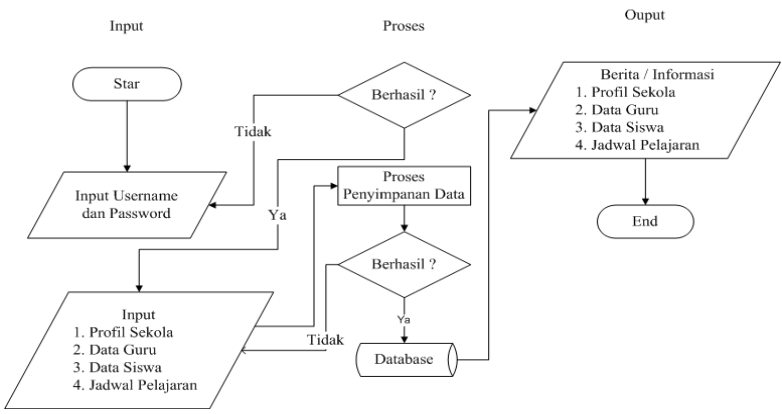

Gambar 1 : Flowchart Sistem Yang Diusulkan

\section{PERANCANGAN SISTEM}

Tahapan perancangan memeliki tujuan untuk mendesign sistem baru yang dapat menyelesaikan masalah-masalah yang 
dihadapi perusahan yang diperoleh dari pemilihan alternative sistem yang terbaik. Mengenai hal ini Al Fatta (2007:24)

\section{Perancangan Tabel}

\section{a. Tabel Profil}

Tabel profil digunakan untuk menyimpan data yang berhubungan dengan profil. Spesifikasi dari tabel profil adalah sebagai berikut

Tabel 1 : Profil Sekolah

\begin{tabular}{|l|l|l|c|}
\hline Nama & Type & Size & Primary Key \\
\hline Id_profil & Int & 11 & $*$ \\
\hline Judul & Varchar & 10 & \\
\hline Isi & Text & & \\
\hline
\end{tabular}

\section{b. Tabel Data Guru}

Tabel guru digunakan untuk menyimpan data yang berhubungan dengan guru. Spesifikasi dari tabel guru adalah sebagai berikut

Tabel 2: Data Guru

\begin{tabular}{|l|l|l|c|}
\hline Nama & Type & Size & Primary Key \\
\hline Nip & Int & 20 & $*$ \\
\hline Nama & Varchar & 100 & \\
\hline Ttl & Varchar & 100 & \\
\hline Gol & Varchar & 10 & \\
\hline Tmt & Varchar & 10 & \\
\hline Jabatan & Varchar & 50 & \\
\hline Pendidikan & Varchar & 100 & \\
\hline Thn_lulus & Int & 4 & \\
\hline Ijasah & Varchar & 20 & \\
\hline
\end{tabular}

\section{c. Tabel Siswa}

Tabel siswa digunakan untuk menyimpan data yang berhubungan dengan siswa. Spesifikasi dari tabel siswa adalah sebagai berikut

Tabel 3 : Data Siswa

\begin{tabular}{|l|l|l|c|}
\hline Nama & Type & Size & Primary Key \\
\hline Nis & Varchar & 4 & $*$ \\
\hline Nama & Varchar & 100 & \\
\hline Ttl & Varchar & 50 & \\
\hline Alamat & Varchar & 100 & \\
\hline
\end{tabular}

\begin{tabular}{|l|l|l|l|}
\hline Agama & Varchar & 50 & \\
\hline Kelas & Varchar & 10 & \\
\hline
\end{tabular}

\section{d. Tabel Jadwal}

Tabel jadwal digunakan untuk menyimpan data yang berhubungan dengan jadwal. Spesifikasi dari tabel jadwal adalah sebagai berikut

Tabel 4 : Jadwal Pelajaran

\begin{tabular}{|l|l|l|c|}
\hline Nama & Type & Size & Primary Key \\
\hline Id & Int & 11 & $*$ \\
\hline Kelas & Varchar & 100 & \\
\hline Tahun & Int & 4 & \\
\hline file & Varchar & 100 & \\
\hline
\end{tabular}

\section{Diagram Konteks}

Diagram konteks adalah gambaran sistem secara keseluruhan, hanya berisi satu proses yang menggambarkan sistem tersebut terhubung dengan entitas eksternal. Diagram konteks dari Sistem Informasi Berbasis Web pada SMA Negeri 3 Kota Ternate sebagai berikut

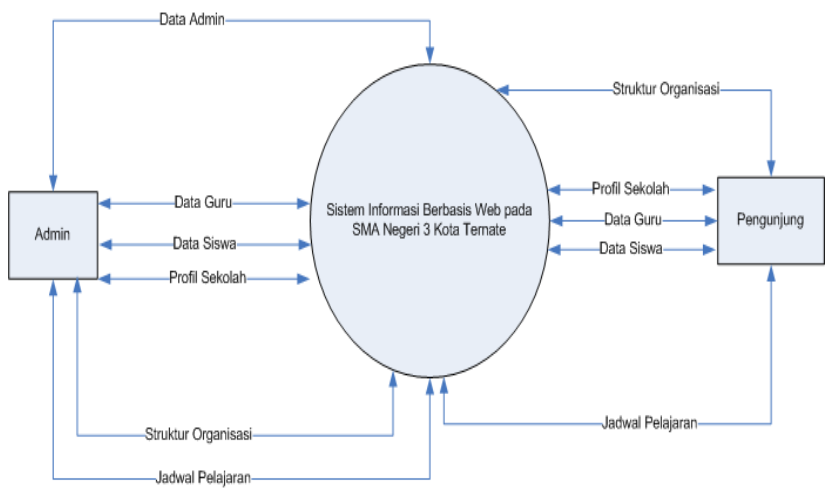

Gambar 2 : Diagram Konteks

\section{DFD Level 1}

Diagram Level 1 dari perancangan sistem dapat dilihat pada gambar sebagai berikut: 


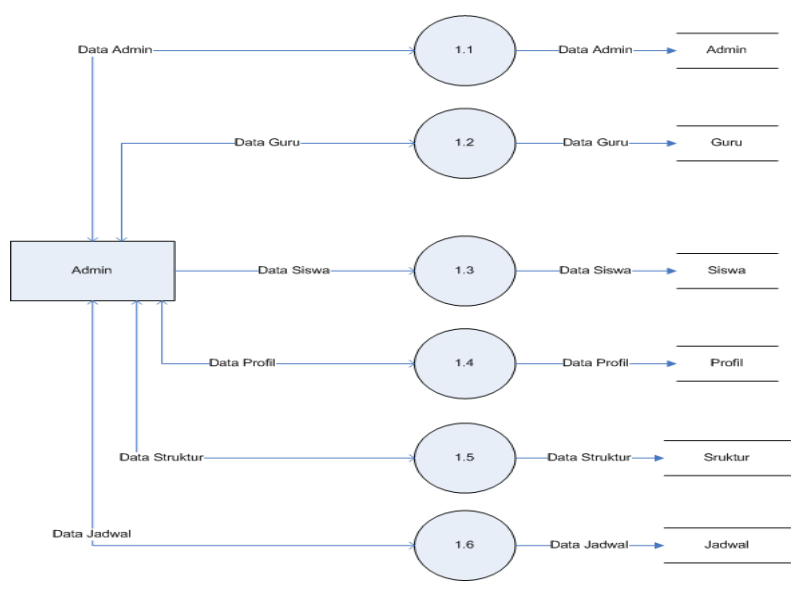

Gambar 3 : DFD Level 1

\section{ERD (entity relationship diagram)}

Entity Relationship Diagram digunakan untuk menggambarkan hubungan yang terjadi pada setiap entitas. ERD dari Sistem Informsai Berbasis Web pada SMA Negeri 3 Kota Ternate ialah sebagai berikut

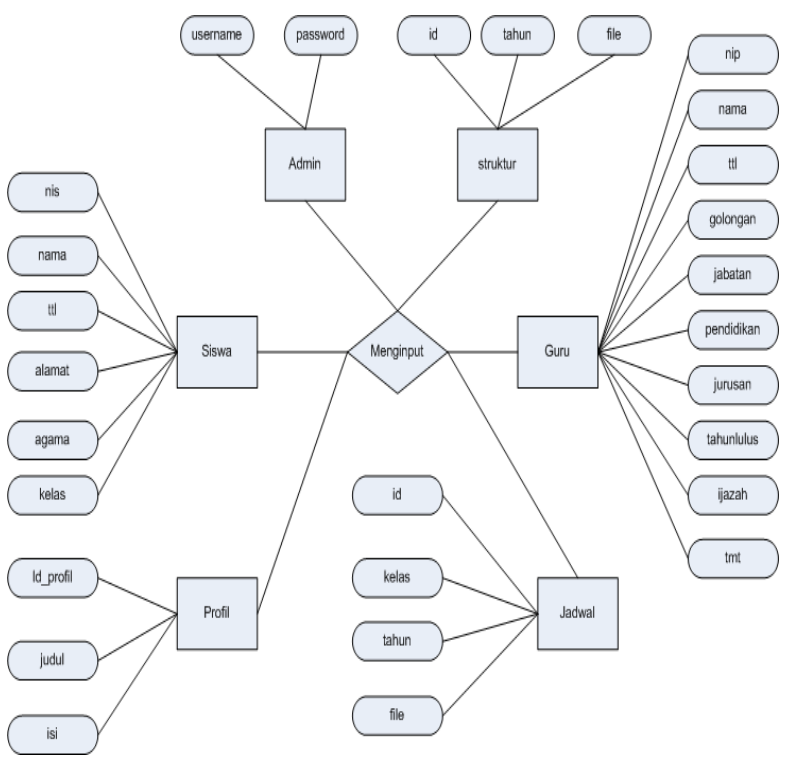

Gambar 4: ERD

\section{IMPLEMENTASI SISTEM}

Implementasi Sistem merupakan tahap peletakan atau pemasangan sistem yang sudah dirancang sebelumnya

\section{a. Login Admin}

Login Admin merupakan menu halaman login dimana admin dapat masuk dengan user name dan Password yang sudah dibuat sebelumnya, Berikut merupakan gambar halaman Login Admin:

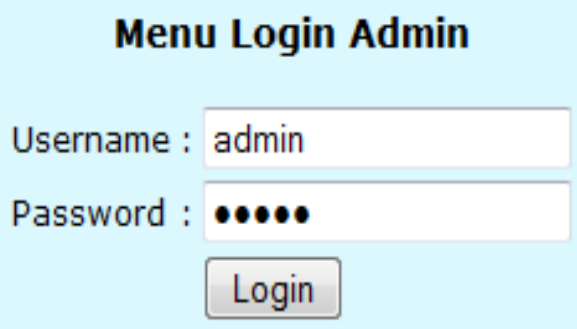

Gambar 5 : Menu LoginAdmin

\section{b. Menu Input Data Profil}

Menu data profil merupakan menu dimana admin dapat menginput dan mengubah data-data profil, Berikut merupakan gambar halaman menu Inout data Profil:

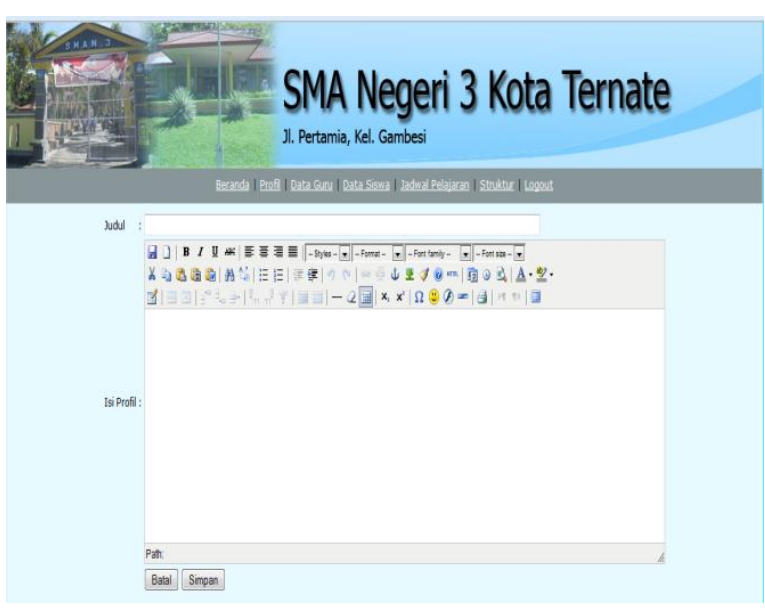

Gambar 6 : Menu Input data Profil

\section{c. Input Data Guru}

Input data Guru merupakan menu halaman dimana admin dapat menginput, Mengubah data-data guru yang ada pada menu input data guru di SMA Negeri 3, 
Berikut gambar halam menu input data guru:
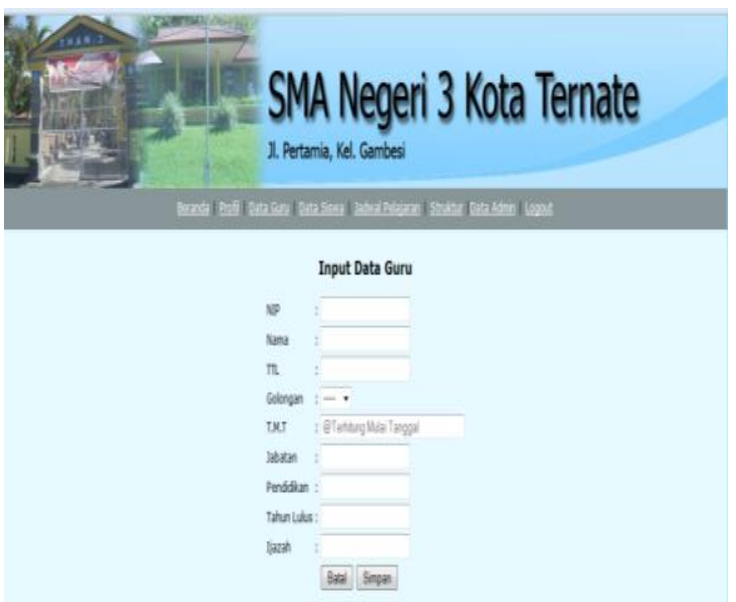

Gambar 7 : Menu Input data Guru

\section{Input Data Siswa}

Input data siswa merupakan halaman dimana admin menginput dan mengubah data-data siswa pada SMA Negeri 3, Berikut gambar input data siswa:

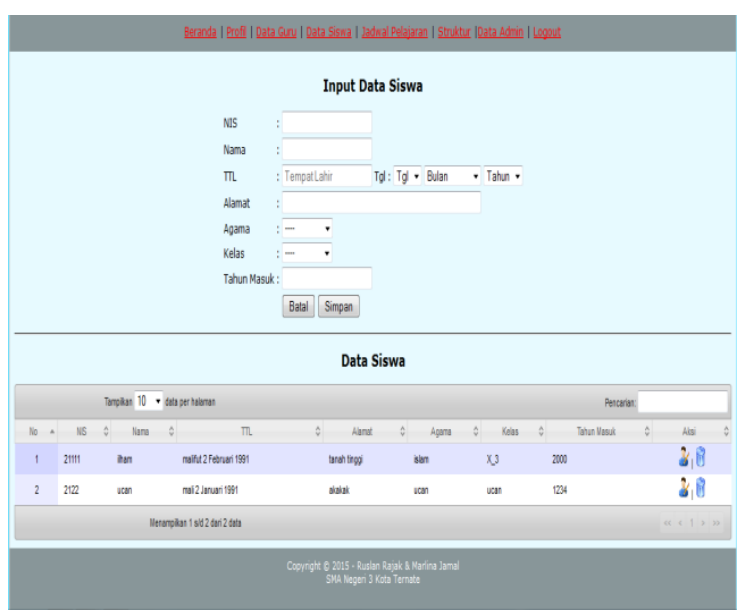

Gambar 8 : Menu Input data Siswa

\section{Menu Halaman Depan}

Menu Halaman depan merupakan tampilan halaman awal dimana pengunjung dapat mengunjungi untuk melihat informasi dan profil dari SMA Negeri 3 Ternate, Berikut gambar tampilan halaman depan

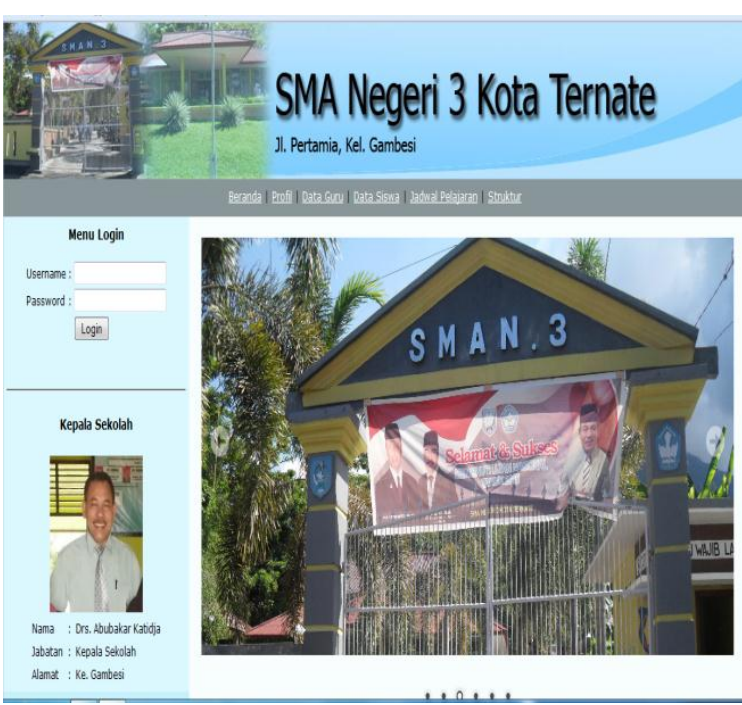

Gambar 9 : Menu Halaman Depan

\section{KESIMPULAN}

Dari hasil penelitian ini dapat disimpulkan bahwa; Sistem yang dibuat ini akan mempermudah pihak sekolah dalam memberikan informasi tentang data siswa kepada pengunjung atau masyarakat, dan dengan sistem ini juga dapat mempermudah pengunjung atau masyarakat untuk mengetahui informasi tentang data siswa tanpa mengenal jarak dan waktu. Disarankan Bagi pihak SMA Negeri 3 Kota Ternate untuk dapat menggunakan sistem ini agar dapat mempermudah dalam memberikan informasi sekolah dimana saja

\section{DAFTAR PUSTAKA}

Jasmadi. Berbagai Teknik Mengupload Web, 2004, Andi, Yogyakarta.

Al Fata Hanaf. 2007. Analisis \& Perancangan Sistem Informasi. AndiOfset, Yogyakarta.

Sutarman. Membangun Aplikasi Web dengan PHP \& My SQL 2007. Yogyakarta : Graha Ilmu

Kadir, Abdul. 2008. Tuntunan Praktis Belajar Database Menggunakan $M y S Q L$. AndiOfset, Yogyakarta. 
Nugroho, Bunafit. 2008. Latihan Membuat Aplikasi Web PHP dan MySQL dengan Dreamweaver.Gava Media, Yogyakarta

Jayan. 2010. CSS Untuk Orang Awam (membangun website tanpa tabel, fleksibel dan \& efektif).Maxikom, Palembang.

Sugiyono, 2012. Memahami Penelitian Kualitatif. CV Alfabeta, Bandung.

Hartono, Bambang. 2013. Sistem Informasi Manajemen Berbasis Komputer. Rineka Cipta, Jakarta

Taufiq Rohmat. 2013. Sistem Informasi Manajemen. Graha ilmu. Yogyakarta.

Saputra, H dan Kawistara,S. 2014. Pemograman Web. Informatika, Bandung

Nur Marlena, Dimas Sasongko, Pembuatan Website Profil Pada Sekolah Menengah Pertama (SMP) Negeri 2 Kartasura, Indonesian Jurnal on Computer Science Speed (IJCSS) 13 - FTI UNSA Vol 9 No 2 - Agustus 2012, ISSN 1979 $-9330$

Sugiyanto, Pembuatan Website Profil sekolah Menengah Kejuruan Pembangunan Nusantara Gabus Groban, Seminar Riset Unggulan Nasional Informatika dan Komputer FTI UNSA 2013, Vol 2 No 1 - Maret 2013 ISSN: 23021136 - seruniid.unsa.ac.id

Dina Khusnia, Berliana Kusuma Riasti, Pembuatan Website Profil Sekolah Menengah Pertama Negeri 1 Kalitidu Bojonegoro, IJNS Indonesian Journal on Networking and Security - Volume 3 No 1 Januari 2014, ISSN: 2302-5700 (Print) 2354-6654 (Online) 